\section{A bit of history}

Irish diaspora is how we refer to the historical process of migration from Ireland, recorded since the Early Middle Ages, but particularly evident since the XVIII century. By the $21^{\text {st }}$ century, an estimated 80 million people worldwide claimed some Irish descent. The online project Historic Graves (https://historicgraves.com) capitalised on this global phenomenon, putting together a worldwide community of more than 15,000 users, engaged in generating a nationwide genealogical dataset.

The initiative started in 2010, as a community focused grassroots heritage project, where local community groups are trained in low-cost high-tech field survey of historic graveyards and recording of their own oral histories.

\section{Local communities}

From the very beginning, the project focused on local communities, a very strong reality in rural Ireland. In the last 9 years, we have worked with over 500 community groups stretching from north Cork in Ireland to Northumberland in England, but the system is global in design. Local communities play a key role in the project, as we rely on them for on-site recording, online transcriptions, training and to solve sensible privacy concerns about specific memorials.

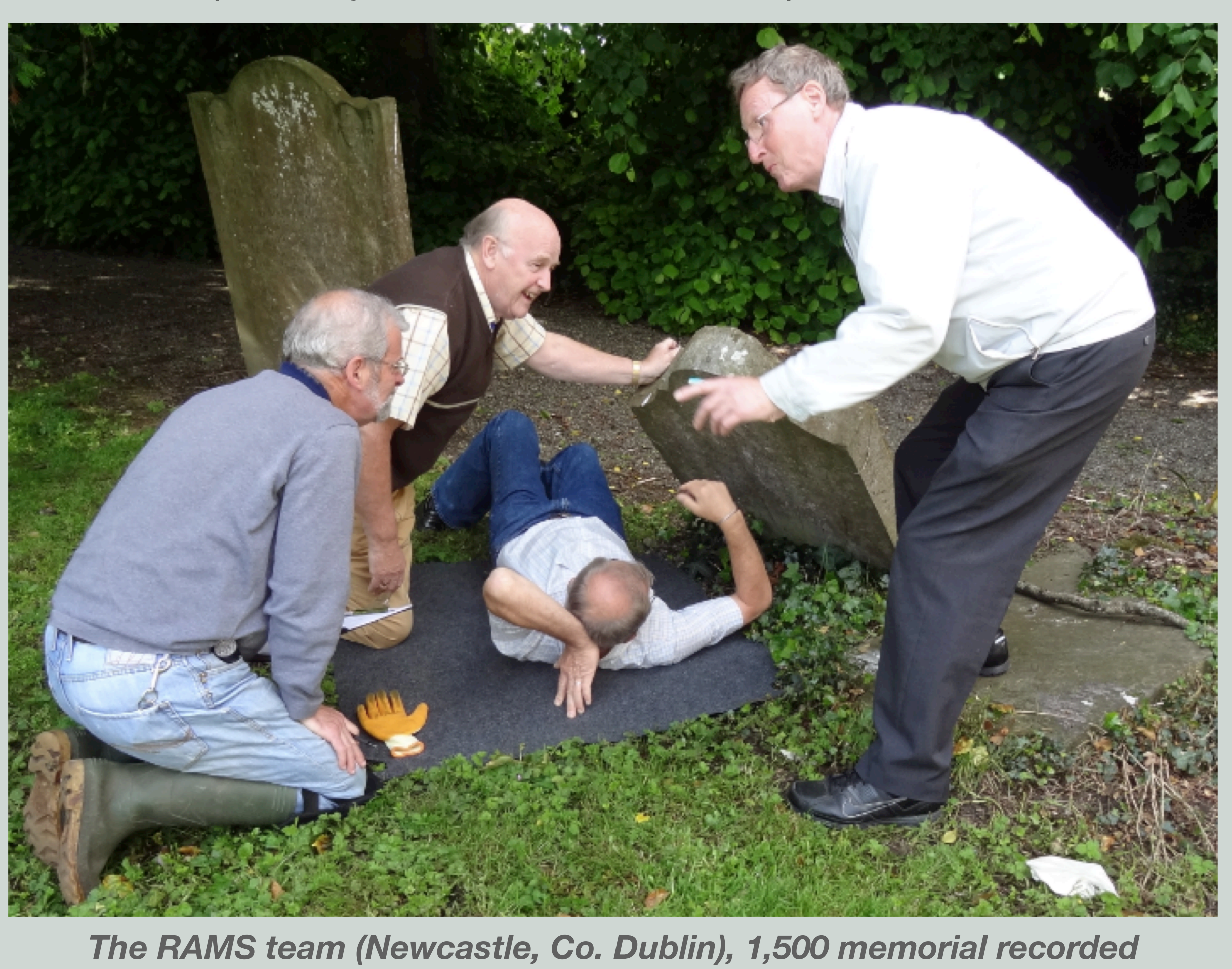

How do we get the communities to trust us? We claim no ownership of the data; they do a large part of the work, community editors can download their corresponding dataset that we ask them to share with the local authority and the funding body, while individual records are available on-line under a Creative Commons license.

After all, we are not creating experiences or collecting opinions - we are primarily building community heritage datasets, that is what brings most visitors to our web platform.

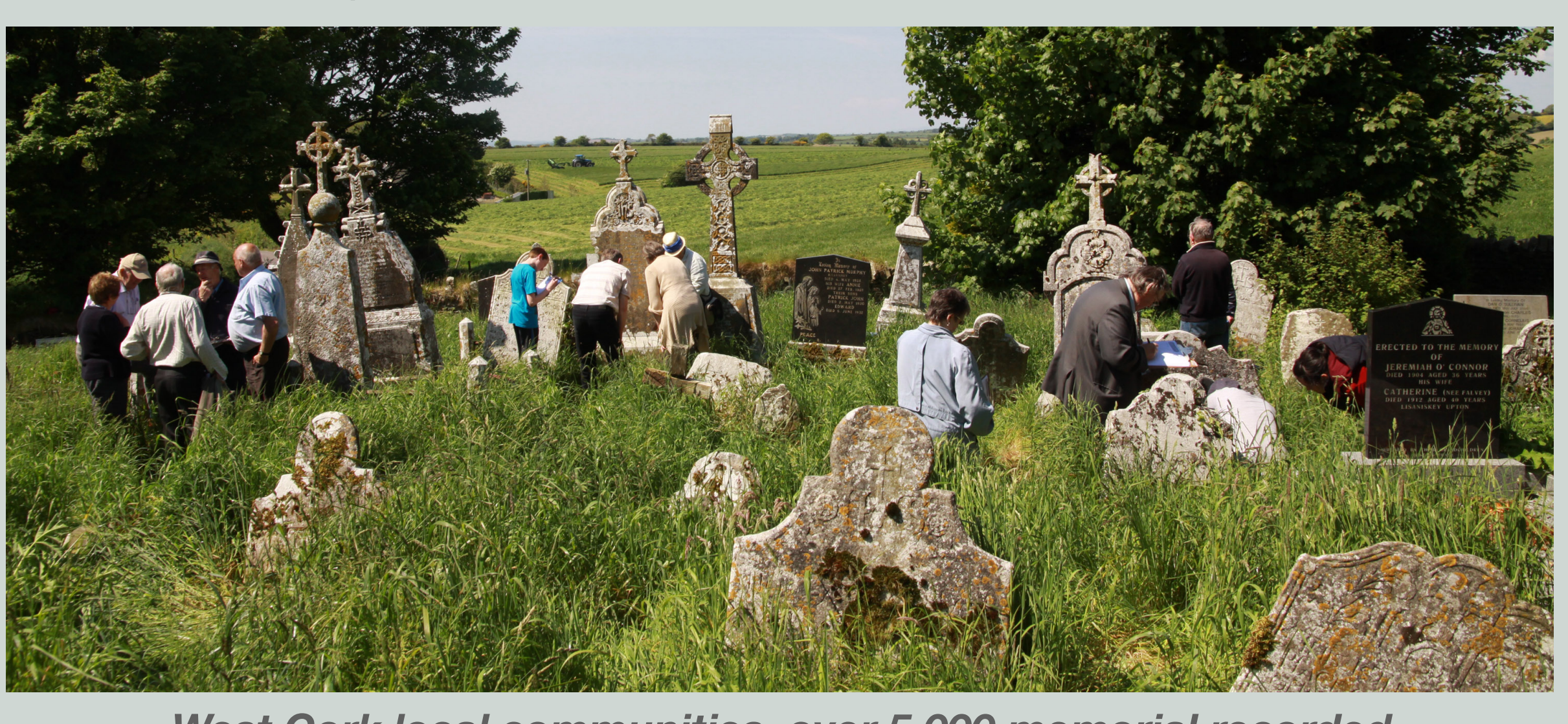

West Cork local communities, over 5,000 memorial recorded

\section{Methodology}

In the project, we record graveyards, mostly over 100 years old, within each graveyard we record all inscribed gravestones (including geolocation) and from each gravestone we register the people listed. Training for an average community group on one site takes normally two days, and we generally get the graveyard surveyed in that time; i.e. approximately 200 headstones surveyed, photographed and read, and the resulting dataset published online.

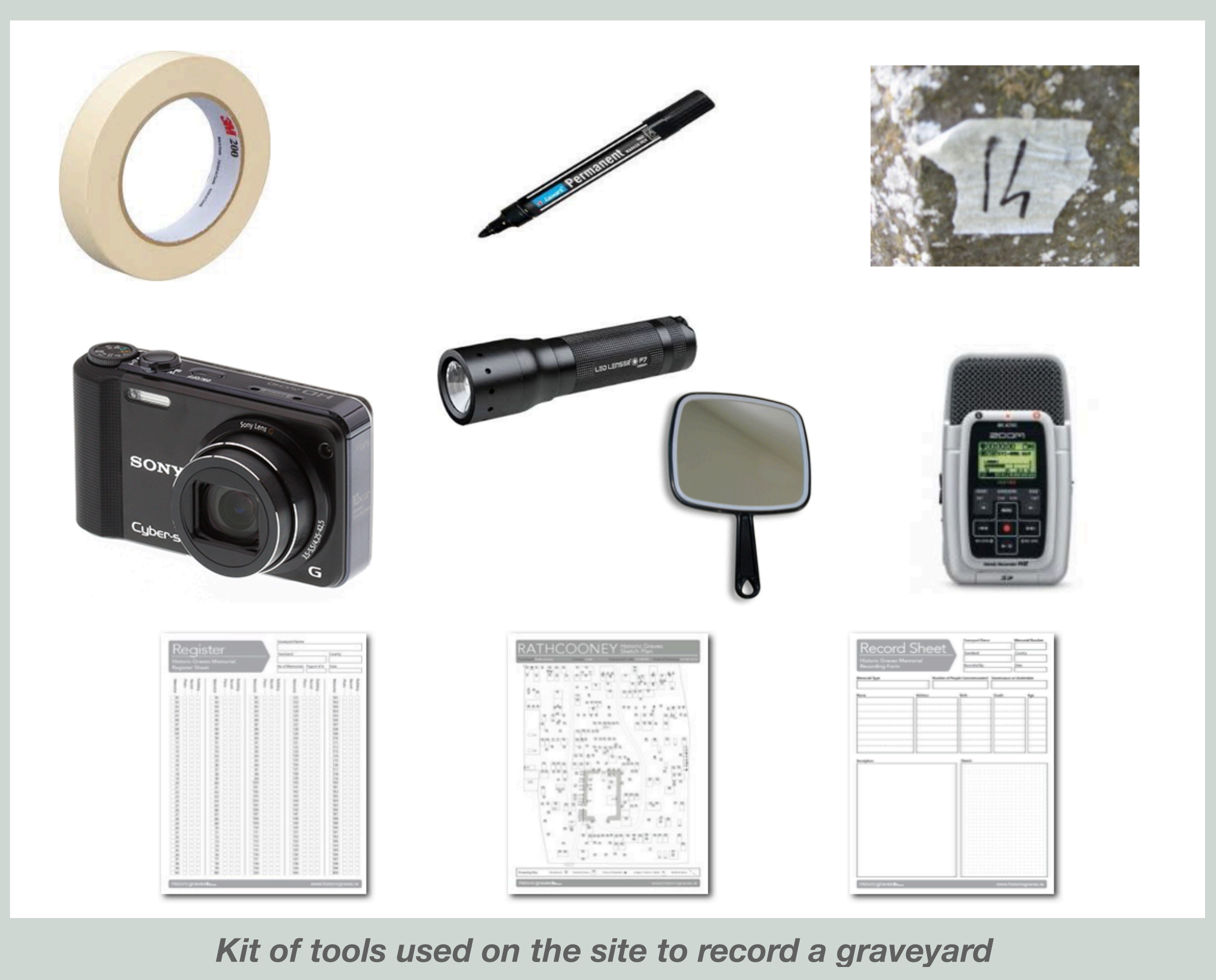

The web-platform, a complete digital ecosystem for community science, and the survey methodology have been designed and built in-house by Eachtra Archaeological Projects, with the aim to be easily usable by small teams of trained volunteers.

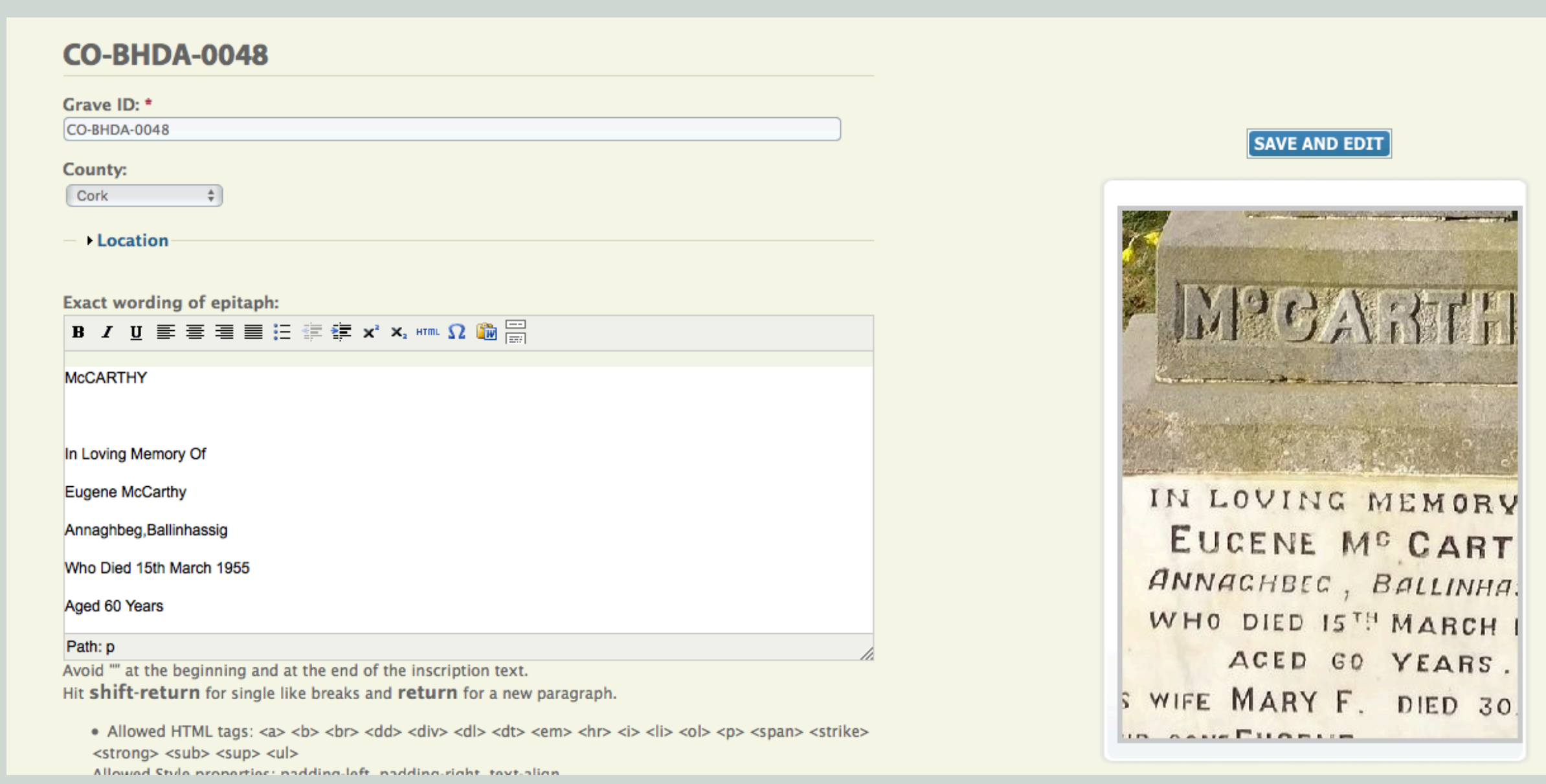

Web interface to transcribe memorials with an enlargeable image

The combination of online interaction and local workshops works best in terms of ensuring meaningful participation. Instant publication proved to be highly engaging for the volunteer groups involved: they see immediate and unmediated results for their transcription work and are willing to share the records with family and friends living abroad. The global community of users takes then responsibility for quality control and completeness.

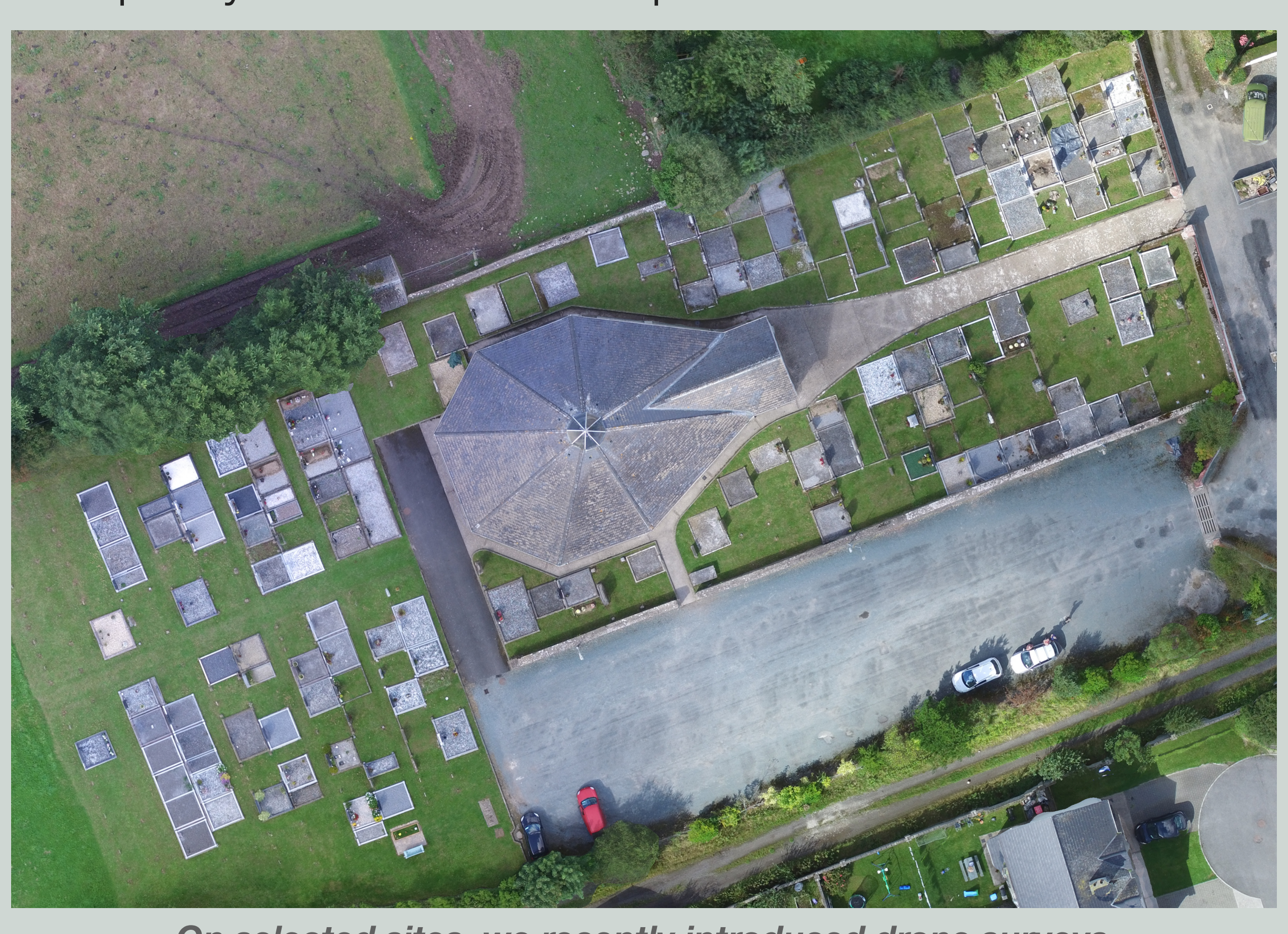

On selected sites, we recently introduced drone surveys
Historic Graves in numbers

Since 2010, historicgraves.com published online more that 800 cemeteries, recording the location of almost 100,000 graves and collaboratively transcribing the details of 195,207 people, and counting.

\begin{tabular}{|c|c|c|}
\hline Graveyards & 836 surveyed & out of $\sim 3600$ estimated \\
\hline Memorials & 92,862 geo-referenced & 66,005 transcribed \\
\hline People & \multicolumn{2}{|c|}{195,207 recorded with at least name and surname } \\
\hline Users & 15650 registered & 116 community editors \\
\hline Monthly users & $\sim 14,000$ & $\sim 80,000$ page views \\
\hline Precedence & Ireland $46 \%$ & UK $16 \%$ \\
\hline
\end{tabular}

Statistics shows that the majority of Irish graveyards is very small in size, with 53\% having less than 50 memorials and over $80 \%$ less then 200. The chronological evolution of monthly deaths shows a sharp decline in Winter Seasonal deceases, towards a less biased distribu- Clustered map of surveyed graveyards tion. This represents just a sneak peak of the informative potential of this crowd-generated dataset, in terms of Irish modern history and genealogy.

Evolution in the percentage of deaths in the different months of the year

\section{Conclusions}

The heritage dataset put together by the Historic Graves project has proved to be a valuable genealogical and touristic asset, allowing people interested in tracing their family history to locate their headstones to individual graveyards, as well as being a source for historical analysis on Irish local and global history, for archaeologists and historians. The project evolved from archaeological professional surveys, focusing on studying the headstones, the burial practices and the representation of power and status, to community archaeology focused on graveyards as living heritage, with both tangible and intangible components.

Local and family historians abound in Ireland and academic historians have formalised their approaches into what is called the History of Families combining genealogy, social history and public history. We have brought the strengths of archaeological fieldwork to the study of the History of Families, whereby we can follow many family groups, via their gravestones, back to the $17^{\text {th }}$ century and to the new communities they formed in distant countries.

III National AIPH Conference, 24th to $28^{\text {th }}$ of June 2019, Università degli Studi della Campania Santa Maria Capua Vetere (Italy)

We average one graveyard survey per week and we run funded training programmes approximately 20 weeks of the year, limited only by available funding. So far, we have received support from a variety of sources including Rural Development Leader funds, Heritage Council grants, as well as from a range of other local authority and government departments. Some groups fund their own projects. In general, we build partnerships where the different partners bring funding, permission and labour, whilst we bring technology and experience. by Maurizio Toscano (Digital humanist, Centre for Irish Studies - Universidad de Granada, linkedin.com/in/mauriziotoscano), John Tierney and Jacinta Kiely.

For further information https://historicgraves.com/contact 